\title{
The S Cell: An Interneuron Essential for Sensitization and Full Dishabituation of Leech Shortening
}

\author{
Christie L. Sahley, ${ }^{1}$ Barbara K. Modney, ${ }^{2,3}$ Nicholas M. Boulis, ${ }^{1}$ and Kenneth J. Muller ${ }^{2}$ \\ 'Department of Biological Sciences, Purdue University, West Lafayette, Indiana 47907, '2Department of Physiology and \\ Biophysics, University of Miami School of Medicine, Miami, Florida 33101 and ${ }^{3}$ Department of Biology, Cleveland State \\ University, Cleveland, Ohio 44115
}

\begin{abstract}
Sensory neurons in the leech excite the $S$ interneuron, which in turn excites motoneurons that shorten the leech, although activity in the $S$ cell reportedly cannot by itself shorten the animal. Experiments were performed in semi-intact leeches using established dishabituation and sensitization protocols. S-cell activity increased during reflexive shortening once the animal was sensitized or dishabituated with a strong shock. S-cell activity otherwise was not associated with shortening. To test the role of the S-cell in dishabituation and sensitization of the shortening reflex, single $S$ cells were ablated in vivo by intracellular injections of pronase. S-cell lesions reduced but did not eliminate dishabituation; however, sensitization was completely disrupted. This was consistent with recent evidence that separate processes contribute to dishabituation and sensitization. Since the $S$ cell in each ganglion is a link in a rapidly conducting chain along the length of the animal, it may be sufficient to break the chain at a single point to eliminate sensitization.
\end{abstract}

[Key words: sensitization, dishabituation, leech, s-cell, learning, S-cell ablation]

Investigations of learning at the cellular level in invertebrates have emphasized changes in sensory neurons and the synaptic connections between them and their postsynaptic targets (Hawkins and Kandel, 1984; Carew and Sahley, 1986; Mpitsos and Lukowiak, 1986; Byrne, 1987, 1990; Hawkins, 1991; Hawkins et al., 1993). More recently, the importance of interneurons and their modulation has been recognized (Frost et al., 1988; Lockery et al., 1989; Trudeau and Castellucci, 1992). In this article we use cell ablating techniques to test the role of the $S$ interneuron in nonassociative learning in the leech Hirudo medicinalis.

In the medicinal leech, behaviors that exhibit nonassociative learning include movement in response to light and to water currents (Ratner, 1972), swimming (Debski and Friesen, 1985, 1986), and local bending (Lockery and Kristan, 1985, 1986, 1991). Like defensive responses in other species, the shortening reflex of the leech habituates in response to repeated tactile or photic stimulation. Regardless of which stimulus modality is used to elicit shortening, a strong stimulus can dishabituate the response. Similarly, sensitization of the shortening reflex can be

Received Nov. 9, 1993; revised Apr. 12, 1994; accepted May 5, 1994.

This work was supported by the Whitehall Foundation (C.L.S.), MH 44789 (C.L.S.), NIH NS 20607 and NSF (K.J.M.), and NRSA MH 10097 (B.K.M.).

Copyright (c) 1994 Society for Neuroscience 0270-6474/94/146715-07\$05.00/0 produced by a strong stimulus. One experimentally favorable feature of the leech is that behavioral training is possible in a semi-intact leech from which changes in neural activity can be measured simultaneously. In addition, single identified cells can be selectively ablated by intracellular injection of protease (Bowling et al., 1978).

One interneuron that, based on its connections, would seem to be involved in shortening is the $\mathbf{S}$ cell. Each ganglion contains a single $S$ cell that is excited by touch via the touch (T) sensory neurons (Gardner-Medwin et al., 1973) acting through a pair of coupling (C) interneurons (Muller and Scott, 1981). The S cells in turn synapse on the $\mathbf{L}$ motor neurons, which act as a pair to shorten all the longitudinal muscles within the segment. In addition to these connections within the ganglion, each $\mathrm{S}$ cell sends an axon into the anterior and into the posterior medial connective halfway to the next ganglia. There the neighboring $S$ cells' axons form an electrical synapse. This strong synapse from segment to segment allows action potentials to propagate up and down the nerve cord. The chain of coupled $\mathrm{S}$ cells is often referred to as the fast conducting system (FCS) of the leech, since the $\mathrm{S}$ cell axon is the largest in the leech and has the fastest conduction velocity (Laverack, 1969; Gardner-Medwin et al., 1973; Frank et al., 1975). The S cells have been shown to be involved in the generalized shortening of the nerve cord (Magni and Pellegrino, 1978); however, their role in whole-body shortening has not yet been clearly demonstrated. The experiments below were designed to investigate the relationships between shortening, S-cell activity, and nonassociative learning.

\section{Materials and Methods}

Preparation, recording, and stimulation. Seventy-five adult leeches obtained from a commercial supplier (Leeches USA, Westbury, NY) or raised in the laboratory were used for these experiments. A semi-intact preparation was used to measure changes in shortening and S-cell activity during nonassociative learning similar to that used previously (Boulis and Sahley, 1988). In brief, the anterior seven segments of the leech remained intact and the anterior sucker was attached to a force transducer that recorded the behavioral response. The leech, except for the nerve cord, was transected at the 9th segment and ganglia 8, 9, and 10 were exposed. The posterior end of the animal and the exposed ganglia were pinned securely to a Sylgard-lined petri dish (see Fig. 1). The connectives posterior to ganglion 12 were placed in a suction electrode for recording neural activity with a Grass P15 preamplifier in experiments 1 and 2. Output from the force transducer and from the suction electrode was recorded on a oscilloscope, a typical record of which is shown in Figure 2 (see also below). In addition, since the sweep speed required to count accurately the action potentials prevented the visualization of the complete behavioral response, the output from the transducer was also recorded on a Gould chart recorder.

Shortening was elicited by a single, capacity-coupled 3-6 V, $3 \mathrm{msec}$ shock delivered through two Teflon-coated silver wires connected to a 


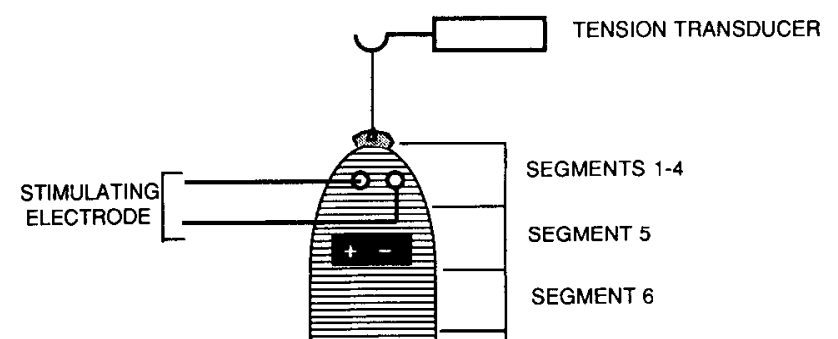

SEGMENT 7

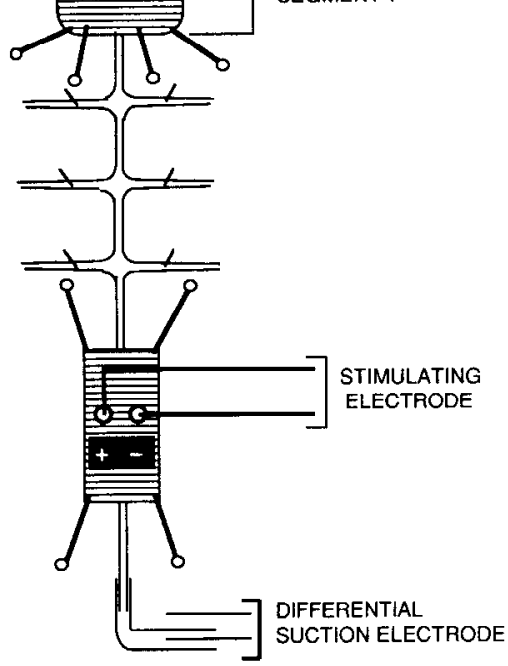

Figure 1. Schematic representation of the semi-intact preparation used in these experiments. The preparation consisted of the intact anterior portion of the leech (segments 1-7) and three exposed ganglia (segments $8-10$ ). The posterior end of the animal remained intact from segment $11-12$, and the remaining conncetives werc dissected and placed in a suction electrode for recording electrical activity in experiments 1 and 2 . In experiments 3 and 4 the posterior connectives were not placed in a suction electrode. The sinus on the connectives caudal to ganglion 12 was removed. This preparation was pinned to a dish, a suture thread was attached to the anterior sucker and connected to a force transducer, and the behavioral response recorded.

stimulator (Grass S88 and SIU5, Grass Instruments, Quincy, MA). These wires were bared near their tips and were inserted anterior to segment 4 under the dorsal skin. By using this electrical stimulus, which is just above threshold for the behavioral response, the touch $(T)$ and pressure $(\mathrm{P})$ mechanosensory neurons are preferentially activated (Sahley, unpublished observations), mimicking a touch stimulus applied to the skin (Nicholls and Baylor, 1968; Muller and Scott, 1981).

The dishabituating and sensitizing stimuli were delivered through identical wires implanted in the posterior portion of the leech at approximately segment 12 . These were two trains of ten 6-9 V, $3 \mathrm{msec}$ shocks delivered at $10 \mathrm{~Hz}$. with a $2 \mathrm{~min}$ ISI. These stimuli have been shown to fire the nociceptive (N) and Retzius (R) cells (Nicholls and Baylor, 1968; Sahley, unpublished observations). The effect of the dishabituating stimulus was assessed by the delivery of three additional test stimuli identical to those that produced habituation.

Behavioral training protocols. After the output from the force transducer attached to the leech had stabilized, the stimulus voltage was adjusted to a level just above threshold for shortening. This level allowed decreases as well as increases in shortening to be observed. The behavioral response to the first stimulus at this level was assigned a magnitude of $100 \%$, and all subsequent responses were expressed as a percentage of the initial level.

Habituation training consisted of 20 trials separated by an interstimulus interval (ISI) of $2 \mathrm{~min}$, after which two dishabituating stimuli were given.

In the sensitization experiments, two stimuli were delivered at a voltage level just above threshold and the average of these two responses was uscd as the initial response level. After obtaining the initial response, two sensitizing trains of stimuli identical to those used for dishabituation
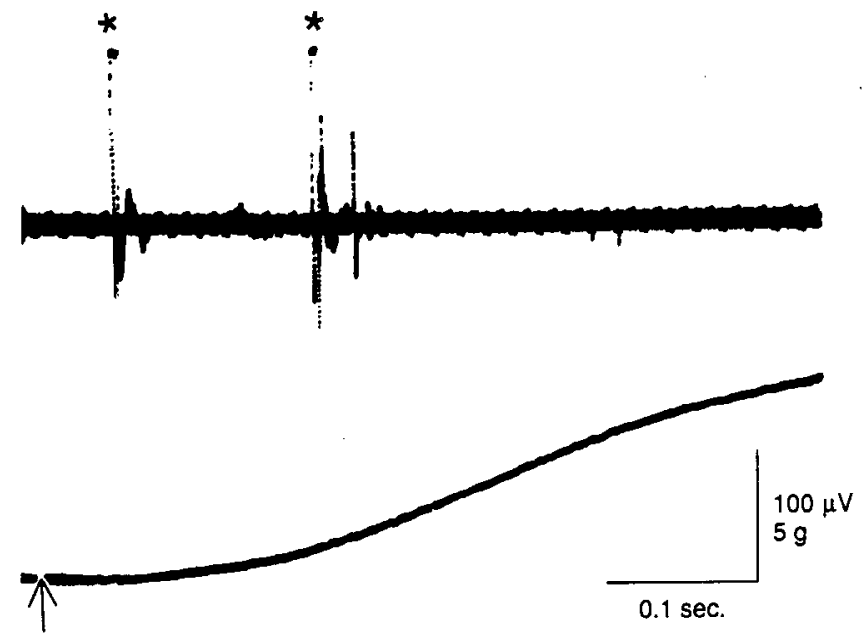

Figure 2. S-cell activity and shortening of the leech in response to skin and body wall stimulation. Electrical stimulation of the skin anterior to segment 4 as described in Materials and Methods elicited in this case two large S-cell action potentials recorded extracellularly from the connective posterior to ganglion 7 (upper trace) followed by a contraction measured with the tension transducer affixed to the animals' head (lower trace). Traces were photographed from the oscilloscope screen.

were applied. Animals then underwent habituation training as described above.

The S-cell axon, the largest in the connectives, produces the largest action potential recorded with extracellular electrodes, as shown in Figure 2, top trace. The firing elicited by a cutancous stimulus precedes a contraction (bottom trace). This cell also fires in response to photic stimulation (not shown), which was used to assure its identity in the extracellular records. For data analysis in experiments 1 and 2 , the number of S-cell spikes that occurred within $500 \mathrm{msec}$ of the skin stimulation was recorded for each trial. As with the behavior, the number of action potentials elicited by the first stimulus was considered $100 \%$ and all subsequent responses were analyzed as a percentage of this level.

Data analysis. Data from the 20 habituation trials were grouped into blocks of five trials and analyzed by a repeated-measure ANOVA and subsequent correlated $t$ tests (experiments 1 and 2) or a mixed twofactor ANOVA with post hoc Newman-Keuls tests to determine between-group differences. The correlation between the magnitude of the shortening reflex and S-cell activity was determined by Pearson's product-moment correlation coefficient $(r)$ (Witte, 1985).

Cell ablation. Complete methods for killing single neurons can be found in Bowling et al. (1978). Animals were anesthetized in $15 \mathrm{~mm}$ chlorobutanol in leech Ringer's, and the fourth segmental ganglion was exposed by making a small incision in the ventral skin and blood sinus. The $S$ cell was identified by its position, size, and characteristic action potential during intracellular recording. Following identification of the cell, a solution of $0.6 \%$ protease (Sigma type VIII) in $0.2 \mathrm{M} \mathrm{KCl}$ and $0.4 \%$ fast green FCF dye was injected under pressure into the cell through a beveled microelectrode. For controls, the ganglion was exposed and, in some cases, cells other than the $\mathrm{S}$ cell, such as the Retzius cell, were injected with protease.

Animals were allowed to recover for 1 week and were assigned codes that allowed subsequent behavioral testing to be done without experimenter knowledge of treatment group.

The animals were tested for habituation, dishabituation, and sensitization according to the methods described above. Following behavioral training, chains of at least three ganglia including ganglion 4 were removed from each animal and placed in $2 \%$ glutaraldehyde in $0.1 \mathrm{M}$ sodium cacodylate buffer, $\mathrm{pH} 7.4$, for $30 \mathrm{~min}$. Following several buffer rinses, the tissue was placed in $1 \%$ osmium tetroxide in $0.1 \mathrm{~m}$ sodium cacodylate huffer for $2 \mathrm{hr}$ and embedded in Epon 812. Semithin sections were cut across the connectives adjacent to ganglion 4 and used to determine if the S-cell axon had been disrupted. If no large-diameter axon was present, the animal was included in the S-cell ablation group. If there was any indication that the $S$ cell had not been disrupted, the 


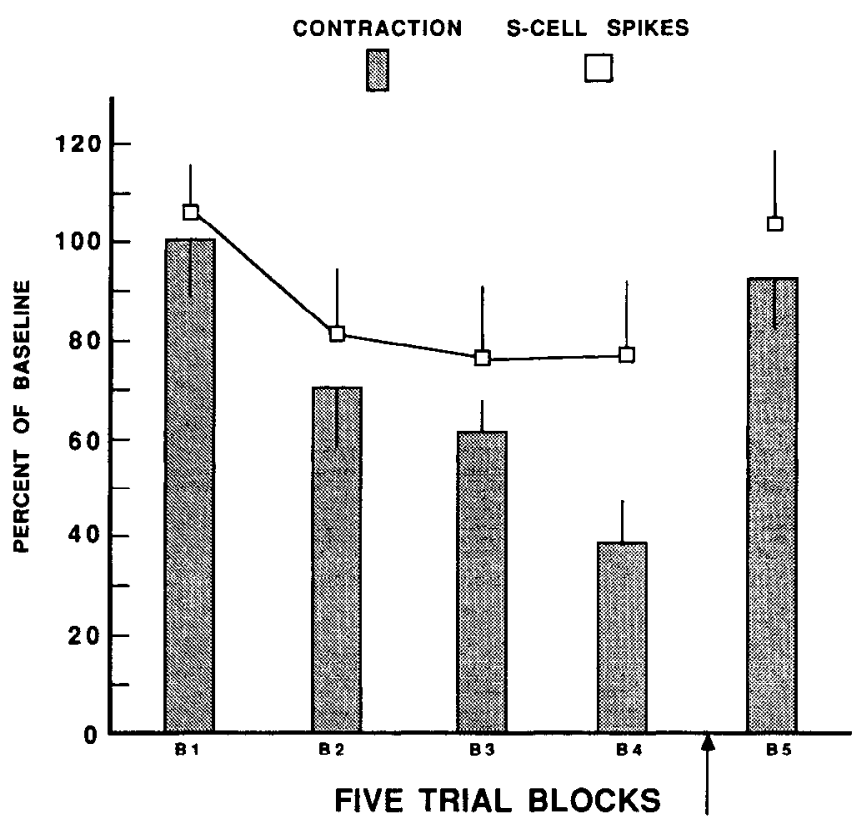

Figure 3. S-cell activity as related to habituation and dishabituation of shortening: Mean percentage initial shortening responses during habituation $(B I-B 4)$ and dishabituation training $(B 5)$ are indicated by bars. Mean initial baseline S-cell activity is shown by open squares and was recorded simultaneously with contraction measurements.

animal was discarded from the data set. The decision to include or discard animals was made without investigator awareness of the results of the behavioral testing.

\section{Results}

\section{Experiment 1. S-cell activity: habituation-dishabituation}

The goal of experiment 1 was to assess the relationship between (1) S-cell spike activity and (2) the behavioral expression of habituation and dishabituation of the touch-elicited shortening reflex. Eight leeches were dissected as described above and suction electrodes were attached to the exposed connectives. Each preparation was trained using the habituation-dishabituation behavioral protocol also presented above. Ten control preparations were held in the dish for the duration of the experiment to assess any decrement in responding that might occur owing to the time in the dish. Previous experiments indicated that animals not experiencing habituation training showed no decrement in responding (Boulis and Sahlcy, 1988); however, no $\mathrm{S}$-cell recordings were made.

Behavior. The mean percentage initial contraction across training trials during habituation and dishabituation is presented in Figure 3. The mean initial contraction measured 5.98 $\pm 0.855 \mathrm{gm}$. As seen in the figure and revealed by the ANOVA, the amplitude of the reflex showed a decrease in responding across habituation trials, from B1 (100.4 $\pm 9 \%)$ to B4 (38 \pm $11 \%$ of initial baseline) [trial block effect, $F(3,28)=6.46, p<$ $0.01]$. The Newman-Keuls post hoc analyses indicated that there was a significant decrease in responding from block 1 to block 2 ( $p<0.01$ ); no change in responding from block 2 to block 3 and a second significant decrease in responding from block 3 to block $4(p<0.05)$. Control preparations showed no significant decrement in responding between baseline testing and test trials, which occurred at the time corresponding to block 4 in Figure 2 ; they continucd to respond at $99.2 \pm 4.2 \%$ of their initial contraction $[t(9)=0.563, p>0.6]$.
A correlated $t$ test used to assess the effect of the dishabituating stimulus indicated that the leeches showed a significant increase in responding following the presentation of the noxious stimulus from $39 \%$ to $92 \pm 10 \%$ of their initial responding $[t(7)=5.35$, $p<0.01]$.

$S$-cell activity. The mean percent initial $S$-cell activity is also presented in Figure 3. Baseline S-cell activity evoked by the touch stimulus averaged $6 \pm 0.43$ action potentials. In contrast to the behavior, no significant decrease in touch-elicited S-cell spiking was observed across the four habituation blocks [ANOVA, $F(3,28)=0.77, p>0.5$ ]. $\mathrm{Bl}$ responding was approximately $117 \pm 16 \%$ of baseline ( 6.8 action potentials) and $B 4$ responding was at $77 \pm 11 \%$ (4.6 action potentials). To get a better idea of the relationship between the S-cell firing and the behavior, correlations between the two dependent measures were calculated using trial by trial data. The correlation coefficient for habituation indicated that there is no relationship between the response amplitude and the S-cell spiking during habituation (correlation coefficient $=0.181, r^{2}=0.033$ ). The $r^{2}$ value indicates that only $3.3 \%$ of the total variability in behavior is associated with variability in S-cell spiking (Witte, 1985), suggesting that other cells mediate habituation of the reflex. The correlation coefficient for dishabituation $\left(0.603\right.$ and $\left.r^{2}=0.364\right)$ indicates a stronger positive correlation between the observed $S$-cell spiking and the response magnitude. That is to say, for dishabituation $36.4 \%$ of the variability in behavior can be accounted for by the variability in $\mathrm{S}$-cell spiking. It is clear the $\mathrm{S}$ cell is active during habituation of the shortening reflex, but the firing of the $S$ cell to the repcatcd prescntation of the test stimulus does not track the decrease in behavior observed as a result of habituation training. When the dishabituating stimulus that increases the amplitude of the behavioral response is presented, however, a greater degree of correlation between $S$-cell firing and the behavioral response is observed. Yet, for dishabituation S-cell activity accounts for less than $40 \%$ of the variability in the behavior, suggesting that other cells make important contributions to the dishabituation of the reflex.

No significant differences were observed in S-cell activity for control leeches; $S$-cells continued to fire at $98.2 \pm 4.8 \%$ of their initial firing rate $[t(9)=0.775, p>0.5]$.

\section{Experiment 2. S-cell activity: sensitization}

The goal of experiment 2 was to assess the role of the $S$ cell in sensitization of the touch-elicited shortening reflex. Based on evidence that an increase in responding is observed in the FCS as a result of a noxious dishabituating stimulus (Bagnoli et al., 1975), it has been suggested that the FCS is important for sensitization. However, no direct measurement of S-cell (FCS) spike activity has been made in a sensitized preparation. In experiment 2, simultaneous S-cell activity and behavioral measurements were made for leeches experiencing sensitization training $(n=12)$ and for a control group that did not experience the sensitization training $(n=10)$.

Behavior. The mean percentage initial contraction for leeches in the sensitization and sensitization control groups are presented in Figure 4. Responses to the test stimulus were significantly greater for leeches in the sensitization group as compared to leeches in the control group, $118 \%$ versus $67 \%$ of baseline values, respectively. The ANOVA, revealed a significant group effect $[F(1,21)=35.17, p<0.001]$. In addition, the significant group $\times$ block interaction $[F(3,63)=3.77, p<0.01]$, indicatcd that performance for leeches in the two groups differed across 
trial blocks. The Newman-Keuls post hoc analyses indicated that no significant differences were observed across training blocks 1 and 4 for animals in the shock group; in contrast, animals in the NS group showed a significant decrement in response amplitude from block 1 to block 4 ( $p<0.05$ ).

$S$-cell activity. The mean percent initial spike rates for leeches in the sensitization and nonsensitization groups also are presented in Figure 4. As indicated in the Figure and revealed by the ANOVA, the sensitized group showed a greater number of S-cell spikes evoked by the touch stimulus across training, an average of $8.66 \pm 0.54$ action potentials, approximately $115 \%$ of the baseline value, for the sensitized leeches as compared to an average of $5.6 \pm 0.43$ action potentials, approximately $71 \%$ of the baseline level, for the nonsensitized leeches [group effect, $F(1,21)=28.6, p<0.001$; block effect, $F(3,63)=9.74, p<$ 0.001 ; the group $\times$ block interaction did not reach significance]. The correlation results indicate that there was a positive linear relationship between the number of $S$-cell spikes and the reflex amplitude evoked by the touch stimulus as a result of sensitization. The corrclation cocfficicnt of 0.84 and $r^{2}$ of 0.71 indicate that $71 \%$ of the variability in behavior is accounted for by the variability in S-cell activity and a two-tailed test indicated that this relationship was not due to chance $(p<0.05)$. This is a much stronger correlation between $S$-cell activity and the reflex amplitude than obtained for either habituation or dishabituation, thus suggesting the $\mathrm{S}$ cell may be more important for the behavioral expression of sensitization than habituation or dishabituation.

\section{Experiment 3. S-cell ablation: habituation-dishabituation}

The correlative data reported in the previous two experiments suggests that the $\mathrm{S}$ cell may be important for the behavioral expression of dishabituation and sensitization but not for habituation. However, there are many difficulties inherent in the interpretation of correlations and, although informative, these results provide no indication of the causal relationship between behavior and $\mathrm{S}$-cell activity. For this reason intracellular pronase injections were used to ablate $S$ cells selectively; the effect on behavior was assessed. Twenty leeches were selected and randomly assigned to either the control or lesion group, a single $S$ cell was injected with pronase, and behavioral training began approximately $10 \mathrm{~d}$ following surgery as described in Materials and Methods. Injection of protease blocked conduction along the chain of $S$ cells within hours, but remnants of the injected cell may have persisted several days (Fig. $5 A$ ). Only the injected $\mathrm{S}$ cell and not $\mathrm{S}$ cells previously electrically coupled to the ablated $\mathrm{S}$ cell were injured by the injection (Fig. $5 B$ ).

Habituation. The mean percentage initial response amplitude for leeches in the ablated and sham groups is presented in Figure 6. As seen in the figure, leeches in both groups showed a decrease in responding across trial blocks. The ANOVA revealed a significant trials effect $[F(3,54)=36.103, p<0.001]$. No significant group effect or group $\times$ trials interaction was obtained. Newman-Keuls post hoc analyses for the significant trials effect indicated that there was a significant decrease in responding between each of the trial blocks $(p<0.01)$. In addition, no differences were found in the initial amplitude of the reflex ( $p$ $>0.8$ ) or in the test stimulus intensity needed to evoke the reflex $(p>0.7)$. Thus, as suggested by the recording results presented in experiment 1 , the $\mathrm{S}$ cell is not critical for the touch elicited shortening reflex and appears to play little or no role in habituation of the reflex.
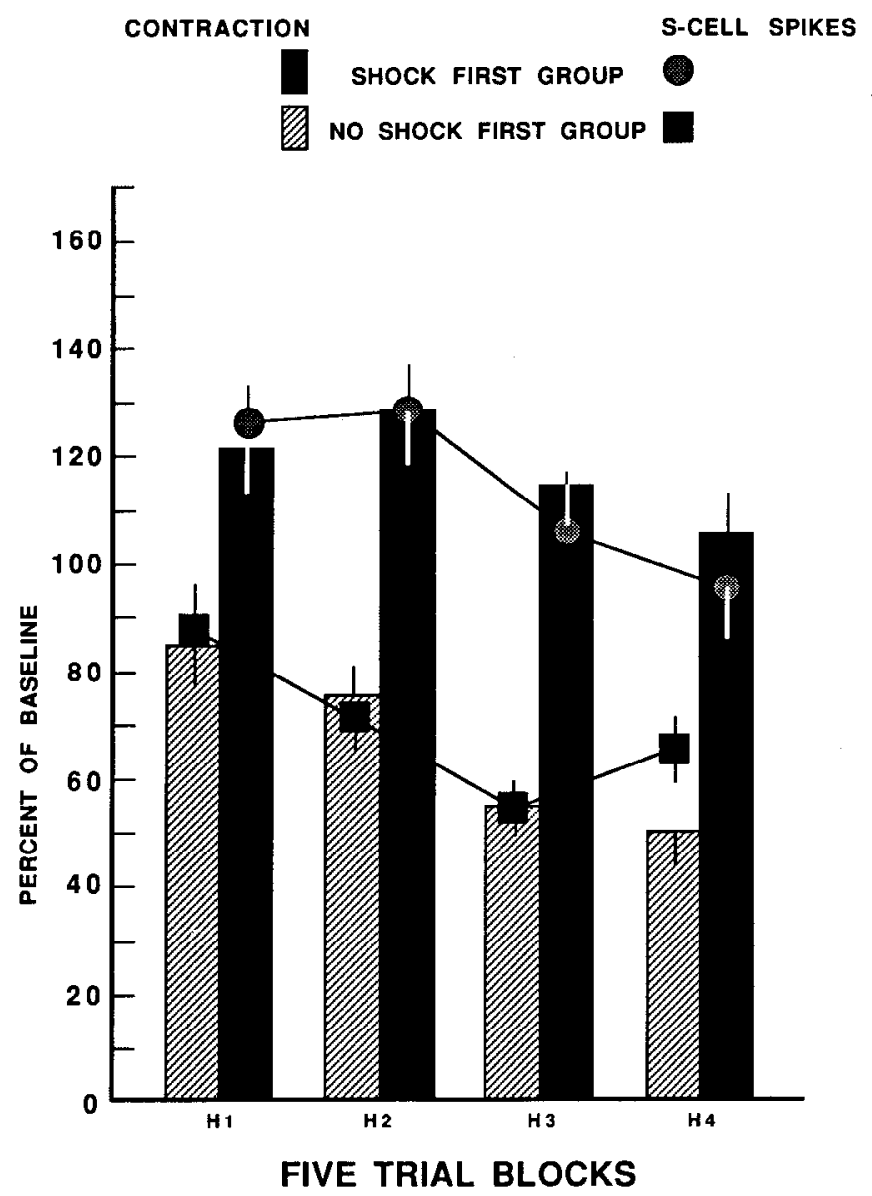

Figure 4. S-cell activity and sensitization: Mean percentage initial baseline shortening and simultaneous S-cell activity following sensitization training. Leeches in the shock-first group (sensitized) responded significantly more to the repeated presentations of the test stimulus (habituation training) compared to nonsensitized leeches $(p<0.01)$ and showed no evidence of habituation. Their scores on block 4 were not significantly different from block 1 . Leeches in the no-shock group showed a significant decrement in response amplitude from block 1 to block 4 $(p<0.01)$. S-cell activity elicited by the touch stimulus was significantly elevated following the sensitizing stimulus and remained elevated throughout habituation training.

Dishabituation. In contrast to habituation, the $S$ cell appears to be important for complete dishabituation of the reflex. The mean percentage initial response amplitudes for leeches in the ablated and sham groups are presented in Figure 6. For leeches in both groups, the dishabituating stimulus caused an increase in responding. As seen in the figure and supported by the ANO$\mathrm{VA}$, leeches in the sham control group show significantly more dishabituation than leeches in the ablated group [group main effect, $F(1,18)=21.744, p<0.001$; group $\times$ trial block interaction, $F(1,18)=57.6, p<0.01]$. However, dishabituation is not completely eliminated by the $S$-cell ablation, leeches in the experimental group showed a significantly greater response following the dishabituation stimulus than on the last block of habituation $[t(7)=2.39, p<0.05]$.

\section{Experiment 4. S-cell ablation-sensitization}

The goal of this experiment was to assess the contribution of the $S$ cell to behavioral sensitization. As in the previous experiment, individual $S$ cells were injected with pronase and the effect of this injection on the behavior was assessed. 

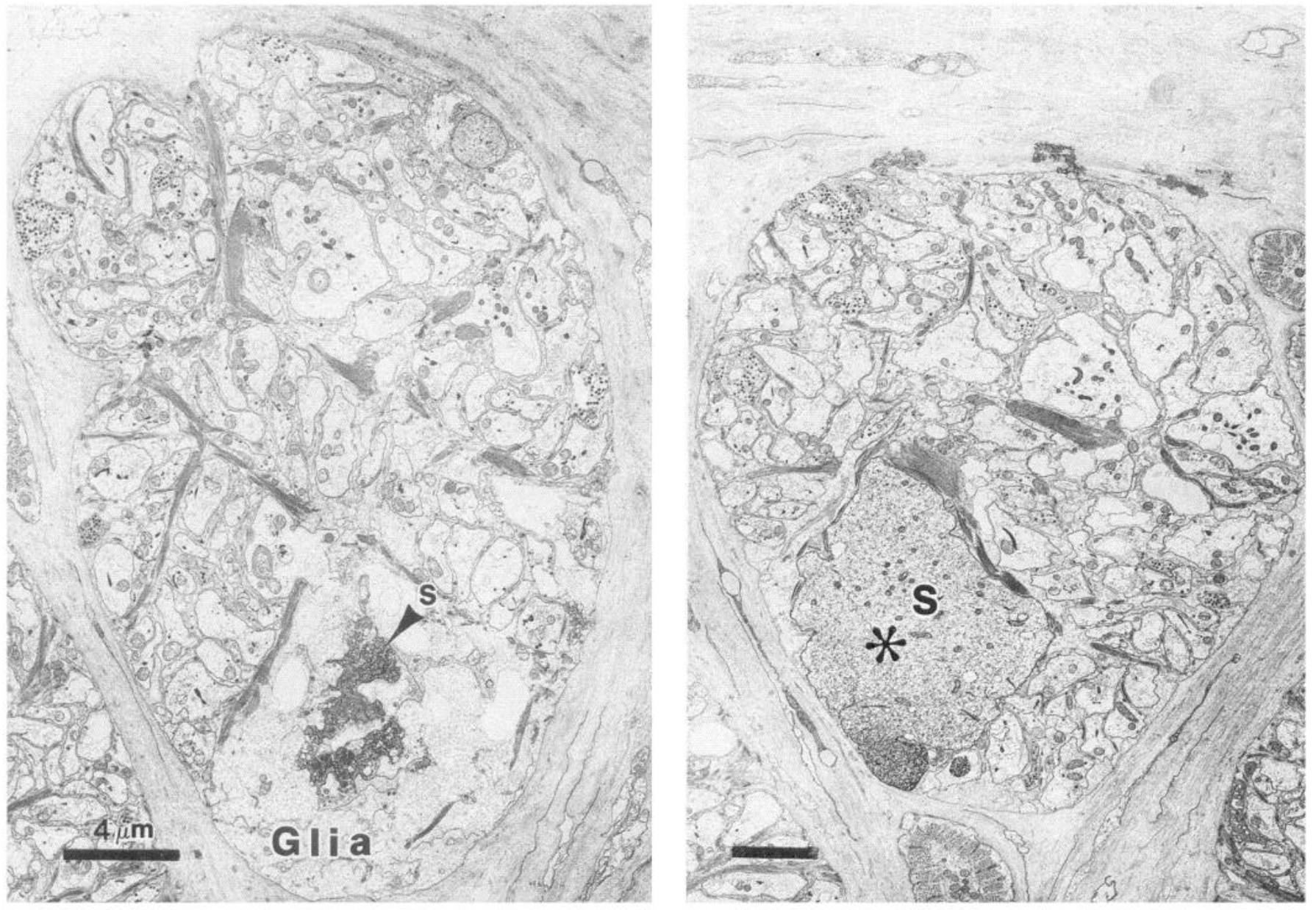

Figure 5. The S-cell was selectively destroyed by intracellular injection with protease. A, Cross section of the medial connective, Faivre's nerve, showed that by $2 \mathrm{~d}$ after injection of protease into its soma, all that remained of the $\mathrm{S}$ cell's axon was a cluster of mitochondria (arrowhead) surrounded by a hypertrophied glial cell. $B$. Cross section taken a few micrometers farther along the nerve shows the neighboring $\mathbf{S}$ cell, injected with HRP to mark it. The HRP-injected $S$ cell, to which the ablated neuron had been electrically coupled, remained intact and looked normal.

Fifteen leeches were randomly selected and assigned to the ablation $(n=8)$ or sham $(n=7)$ groups. Cell ablation and behavioral testing was carried out as described in the previous experiment. The mean percentage initial responding for leeches in the ablation and sham control groups across trial blocks is presented in Figure 7. The ANOVA revealed a significant group effect $[F(1,13)=5.67, p<0.05]$ and a significant block effect $[F(3,39)=7.2, p<0.001]$. The group $\times$ block interaction was not reliable $(p>0.2)$. As indicated by the analysis and shown in Figure 7, leeches in the sham-control group responded significantly more across blocks than did leeches in the ablation group. These data are consistent with the touch-elicited S-cell activity observed in experiment 2 but indicate a greater role for the $\mathrm{S}$ cell in sensitization than predicted from the $\mathrm{S}$-cell recordings.

\section{Discussion}

Until now there has been no known function for the $\mathrm{S}$ cell, despite knowledge of some of its connections and the prominence of its axon suggesting involvement in "escape." Significantly, its activity is neither necessary nor sufficient to cause shortening. The present results demonstrate that this interneuron is necessary for sensitization and normal dishabituation of the shortening reflex. The first clue that the cell might play a role in the modified shortening reflex came from the measurement of S-cell activity during behavioral training. This approach demonstrated that S-cell activity was significantly correlated with the sensitized reflex, but not with the habituated reflex. Of course the positive correlation by itself does not prove that the $\mathrm{S}$ cell is necessary for nonassociative learning. Its necessity was revealed by the profound behavioral deficits observed following deletion of the cell in ganglion 4. Interestingly, the results support the idea that the $\mathrm{S}$ cell is not required for shortening, since its ablation had no effect on baseline measures of shortening or its habituation.

In the present experiment it is not clear exactly which neurons participate in the baseline reflex and which neurons are responsible for producing the modified response. It is interesting that killing an $\mathrm{S}$ cell differentially affects dishabituation and sensitization, suggesting that the circuits generating the responses might be different for the two modified reflexes. The dissociation of dishabituation and sensitization has been noted before by several authors using a variety of cellular and behavioral procedures (Marcus et al., 1988; Rankin and Carew, 1988).

Among those neurons that could be important in the shortening reflex are three types of mechanosensory neurons: touch 


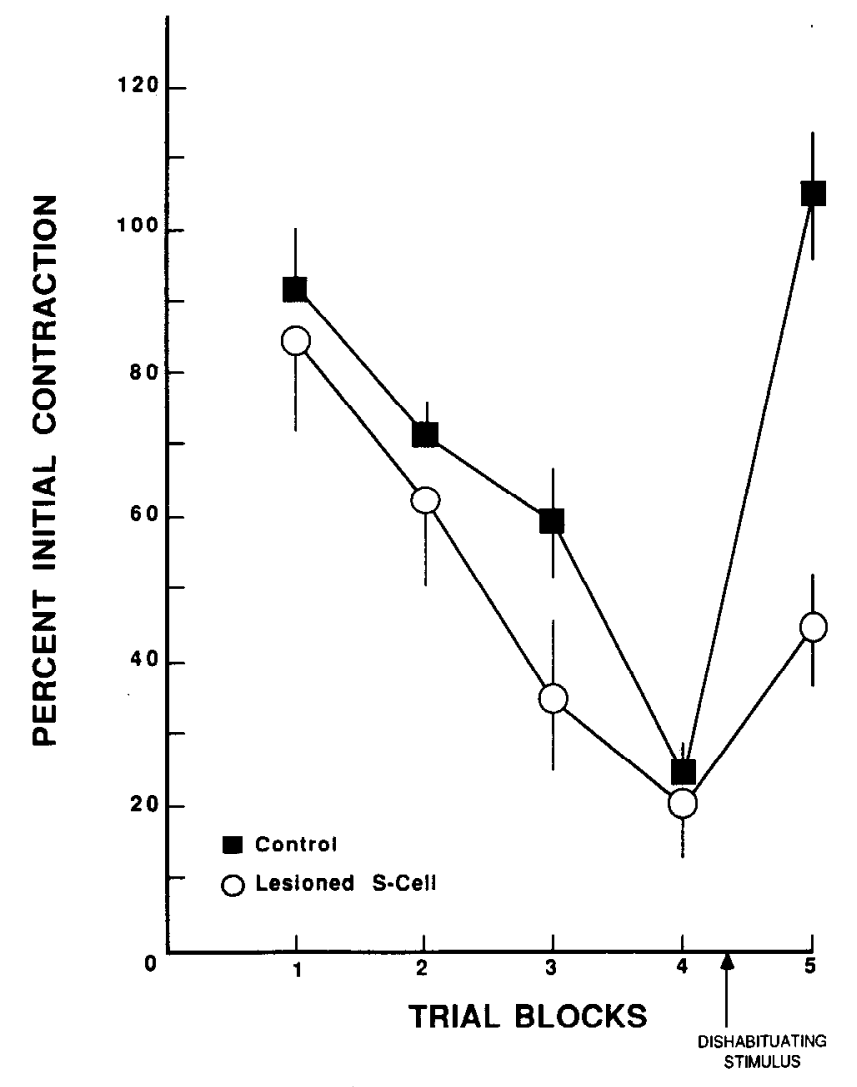

Figure 6. Effect of S-cell kill on habituation and dishabituation. The mean percentage initial shortening reflex amplitudes across training are presented for the nonlesioned and S-cell-lesioned leeches. No significant differences between the two groups were observed across habituation training $(p<0.1)$. In contrast, nonablated leeches dishabituated significantly more than the ablated leeches $(p<0.01)$. However, the S-cell ablation did not eliminate dishabituation. The responses for leeches in both groups following the dishabituating stimulus were significantly increased over their block 4 responding $(p<0.01)$.

(T) cells, pressure $(\mathrm{P})$ cells, and nociceptive $(\mathrm{N})$ cells. These cells make monosynaptic excitatory connections with longitudinal (L) motor neurons that innervate the longitudinal muscle that is responsible for body shortening. Recently, Wittenberg and Kristan (1992) have identified additional interneurons and motor neurons that are active during the shortening reflex.

Several authors have speculated that the $S$ cell acts as a general arousal system. While investigating habituation of swimming in the leech, Debski and Friesen (1986) noted a decrement in S-cell activity during habituation trials similar to the decrements observed in the present experiments. However, they too found that the decline in activity did not match the decline in behavior. Because swimming can be induced by intense intracellular stimulation of the $\mathbf{S}$ cell, they suggested that its activity could contribute to swim initiation. Although the role of the $S$ cell in swimming and shortening may seem dissimilar at first, it appears that S-cell activity during both behaviors may represent a state of arousal and not be associated with a specific activity. Just as S-cell activity may be important for the initiation of swimming, it appears that the $S$ cell may be important for facilitation of the shortening reflex.

While the $\mathbf{S}$ cell is necessary for sensitization and contributes to dishabituation, it is unlikely that S-cell activity by itself causes learning or is the basis for it. Recently, it has been shown that

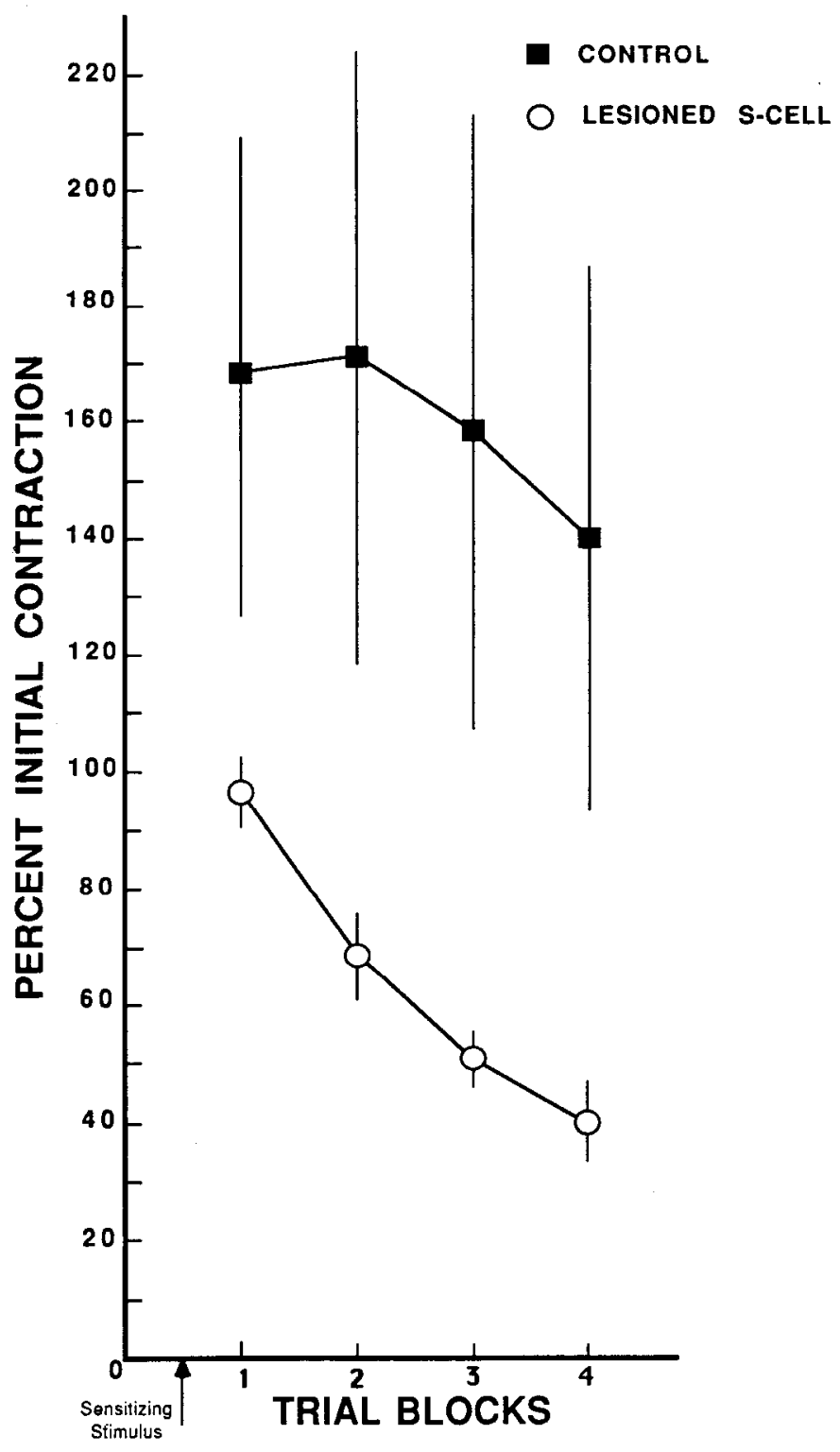

Figure 7. Mean response initial amplitude of the shortening reflex for control and S-cell-ablated leeches following sensitization training. The data are plotted in five trial blocks. The sensitizing stimulus was delivered $2 \mathrm{~min}$ after the last baseline measurement. The effect of the sensitizing stimulus was assessed on the subsequent habituation training, which began $2 \mathrm{~min}$ after the sensitizing stimulus. Leeches in the control group responded significantly more than leeches in the S-cell-ablated group throughout testing $(p<0.01)$. There was no evidence for sensitization in the S-cell-ablated leeches.

nonassociative learning of the shortening reflex can also be eliminated by depletion of serotonin (5-HT) (Ehrlich et al., 1992). $\mathrm{S}$ cells, incidentally, do not contain 5-HT; they were originally, but erroneously thought to be syncytial, hence the apellation $\mathrm{S}$ cells. The results of the 5-HT depletion experiments were virtually identical to the results obtained following S-cell ablations. Namely, sensitization of the reflex was eliminated, dishabituation was reduced but not eliminated, and baseline measures of the reflex were unaffected by depletion. Given the similar deficits produccd by S-ccll ablation and 5-HT depletion, it is tempting to speculate that modification of the shortening reflex requires an interaction between serotonergic cells and the S-cell. Serotonergic neurons have been identified in the leech and appar- 
ently synapse on the $S$ cell (Muller and Carbonetto, 1977), but it has not been determined which neurons are required for modification of shortening. Ehrlich et al. (1992) have speculated that the Retzius cells are important, for they appear to be most affected histologically after 5-HT depletion. Also, physiological results suggest that the Retzius cells are involved in other forms of conditioning (Sahley, 1987). Lockery and Kristan (1986) have suggested that two other pairs of serotoneric neurons in the ganglion, DL and VL, are important for sensitization of the local bending reflex.

Regardless of which serotonergic cells are involved in modifying the shortening reflex, it is clear that both 5-HT and the $S$ cell are required for its modification without being required for the reflex itself. This supports the idea that learning results in a recruitment of cells into a neural circuit that produces the modified response, an idea previously suggested by work in both vertebrate and invertebrate systems. In Aplysia, for example, optical measurements of the electrical activity of hundreds of neurons in the abdominal ganglion showed that nonassociative learning alters activity in 200-300 cells (Zecevic et al., 1989; Wu et al., 1994). Habituation is accompanied by a decrease in the number of active cells. In contrast, more cells are active during dishabituation, the increase in a previously decremented response following a strong stimulus. Likewise in the rabbit, the nicitating membrane conditioned response seems to use brain regions that are not required for the expression of the unconditioned response (Thompson, 1989).

Thus, in the rabbit and Aplysia learning could change behavior by recruiting additional neurons into or eliminating neurons from the neural circuit that generates the behavioral response. This type of circuit reconfiguration plays a critical role in the orchestration of the feeding behavior of the crab and lobster (Harris-Warrick et al., 1992). In the leech, because a single neuron that is recruited into the circuit is essential for modification of behavior, understanding how inputs and excitability of the S-cell change is critically important.

\section{References}

Bagnoli P, Brunelli F, Magni F, Pellegrino M (1975) The neurons of the fast conducting system in Hirudo medicinalis: identification and synaptic connections with primary afferent neurons. Arch Ital Biol 113:21-43.

Boulis NM, Sahley CL (1988) A behavioral analysis of habituation and sensitization of shortening in the semi-intact leech. J Neurosci 8:4621-4627.

Bowling D, Nicholls J, Parnas I (1978) Destruction of a single cell in the C.N.S. of the leech as a means of analyzing its connexions and functional role. J Physiol (Lond) 282:169-180.

Byrne JH (1987) Cellular analysis of associative learning. Physiol Rev $67: 329$.

Byrne JH (1990) Learning and memory in invertebrates. In: Neurobiology of comparative cognition (Kesner RP, Olton DS, eds). Hillsdale, NJ: Erlbaum.

Carew TJ, Sahley CL (1986) Invertebrate learning and memory: from behavior to molecules. Annu Rev Neurosci 9:435-487.

Debski EA, Friesen WO (1985) Habituation of swimming activity in the medicinal leech. J Exp Biol 116:169-188.

Debski EA, Friesen WO (1986) Role of central interneurons in habituation of swimming activity in the medicinal leech. J Neurophysiol 55:977-994.

Ehrlich JS, Boulis NM, Karrer T, Sahley CL (1992) Differential effects of serotonin depletion on sensitization and dishabituation in the leech, Hirudo medicinalis. J Neurobiol 23:270-279.

Frank E, Jansen JKS, Rinvik E (1975) A multisomatic axon in the central nervous system of the leech. J Comp Neurol 159:1-13.
Frost WN, Clark GA, Kandel ER (1988) Parallel processing of shortterm memory for sensitization in Aplysia. J Neurobiol 19:297-334. Gardner-Medwin AR, Jansen JKS, Taxt T (1973) The "giant" axon of the leech. Acta Physiol Scand 87:30A-31A.

Harris-Warrick RM, Marder E, Selverston AI, Moulins M, eds (1992) Dynamic biological networks: the stomatogastric nervous system. Cambridge, MA. MIT Press.

Hawkins RD (1991) Cell biological studies of conditioning in Aplysia. In: Neurobiology of learning, emotion and affect (Madden J IV, ed). New York: Raven.

Hawkins RD, Kandel ER (1984) Is there a cell biological alphabet for simple forms of learning? Psychol Rev 91:375-391.

Hawkins RD, Kandel ER, Siegelbaum SA (1993) Learning to modulate transmitter release: themes and variations in synaptic plasticity. Annu Rev Neurosci 16:625-665.

Laverick MS (1969) Mechanoreceptors, photoreceptors, and rapid conduction pathways in the leech Hirudo medicinalis. J Exp Biol 50: 129-140.

Lockery SR, Kristan W Jr (1985) Neural correlates of habituation and sensitization in the leech. Soc Neurosci Abstr 11:794.

Lockery SR, Kristan WB Jr (1986) Neural correlates of habituation and sensitization of local bending in the leech. Soc Neurosci Abstr $12: 40$.

Lockery SR, Kristan WB Jr (1987) Identified cells cause heterosynaptic facilitation and heterosynaptic depression of the leech local bending reflex. Soc Neurosci Abstr 13:388.

Lockery SR, Kristan WB Jr (1991) Two forms of sensitization of the local bending reflex of the medicinal leech. J Comp Physiol [A] 168: 165-177.

Lockery SR, Wittenberg G, Kristan WB Jr, Cottrell G (1989) Function of identified interneurons in the leech eluciated using neural networks trained by backpropagation. Nature 340:468-471.

Magni F, Pellegrino M (1978a) Neural mechanisms underlying the segmental and generalized cord shortening reflexes in the leech. $J$ Comp Physiol 124:339-351.

Magni F, Pellegrino M (1978b) Patterns of activity and the effects of activation of the fast conducting system on the behavior of unrestrained leeches. J Exp Biol 76:123-135.

Marcus EA, Nolen TG, Rankin CH, Carew TJ (1988) Behavioral dissociation of dishabituation, sensitization, and inhibition in Aplysia. Science 241:210-213.

Muller KJ, Carbonetto S (1977) A regenerating neurone in the leech can form an electrical synapse on its severed axon segment. Nature 267:450-452.

Muller KJ, Scott SA (1981) Transmission at a "direct" electrical connection mediated by an interneurone in the leech. J Physiol (Lond) 311:565-583.

Rankin CH, Carew TJ (1988) Dishabituation and sensitization emerge as separate processes during development in Aplysia. J Neurosci 8:197211 .

Sahley CL (1987) Sensitization modifies sensory neurons in the leech. Soc Neurosci Abstr 13:615.

Thompson RF (1989) Neural circuit for classical conditioning of the eyelid closure response. In: Neural models of plasticity: experimental and theoretical approaches (Bryne JH, Berry WO, eds). San Diego: Academic.

Trudeau LE, Castellucci VF (1992) Contribution of polysynaptic pathways in the mediation and plasticity of Aplysia gill and siphon withdrawal reflex: evidence for differential modulation. J Neurosci 12: 3838-3848

Witte RS (1985) Statistics, 2d ed. New York: Holt, Rinehart, and Winston.

Wittenberg G, Kristan WB Jr (1992) Analysis and modeling of the multisegmental coordination of shortening behavior in the medicinal leech. I. Motor output pattern. J Neurophysiol 68:1683-1692.

Wu J-y., Cohen LB, Falk CX (1994) Neuronal activity during different behaviors in Aplysia: a distributed organization? Science 263:820 823.

Zecevic D, Wu J-Y, Cohen LB, London JA, Hopp H-P, Falk CX (1989) Hundreds of neurons in the Aplysia abdominal ganglion are active during the gill withdrawal reflex. J Neurosci 9:3681-3689. 